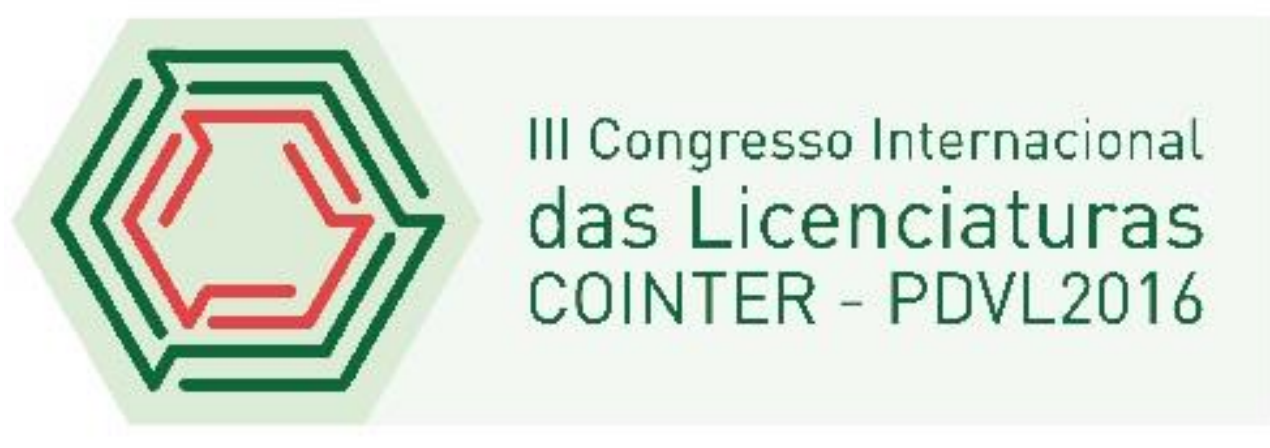

\title{
PERCEPÇÕES DOS ESTUDANTES DO ENSINO MÉDIO SOBRE A RADIAÇÃO NUCLEAR
}

\author{
Apresentação: Comunicação Oral \\ Giselly de Oliveira Silva ${ }^{1}$; Erivaldo Gumercindo de Souza Neto²; Aguinalda Alves Teixeira \\ Filha $^{3}$ Ana Patrícia Siqueira Tavares Falcão ${ }^{4}$
}

\begin{abstract}
Resumo
Muitas pessoas têm medo da radiação nuclear e dos perigos que ela pode trazer a saúde, no entanto, atualmente a radiação é responsável pelo desenvolvimento de áreas como: descoberta e tratamento de doenças, geração de energia, datação de fósseis, conservação de alimentos entre outras. O estudo tem como objetivo investigar as percepções que os estudantes do terceiro ano do Ensino Médio Integrado do Instituto Federal de Pernambuco - Campus Vitória de Santo Antão têm sobre a radiação nuclear. A pesquisa de natureza básica, teve como sujeitos 60 (sessenta) estudantes do terceiro ano do Ensino Médio Integrado ao Técnico de Agroindústria e Agropecuária. Aos estudantes foi aplicado um questionário contendo 3 questões: a primeira questionava o primeiro pensamento que o estudante tem quando escuta a expressão "radiação nuclear", a segunda perguntava se existe radiação nuclear natural, e a terceira solicitava que o estudante marcasse um X no objeto e fenômeno que ele achava que utilizava radiação nuclear. A maior parte dos estudantes têm o primeiro pensamento sobre a radioatividade, negativo (49). O histórico de acidentes e as informações passadas pela mídia, favorecem para que a radiação nuclear seja vista como algo de impacto negativo na sociedade, no entanto os benefícios trazidos pela radiação na saúde, na produção de energia e conservação de alimentos não podem ser esquecidos. A maior parte dos alunos tinham conhecimento sobre a radiação nuclear natural (38). Percebe-se que existe uma troca de conceitos referentes ao conceito de radiação, que é utilizado por muitas pessoas de forma errônea.
\end{abstract}

Palavras-Chave: radioatividade, presença, processos, percepção, ensino médio

\section{Introdução}

O ensino das Ciências Naturais tem se tornado um verdadeiro desafio para os

\footnotetext{
${ }^{1}$ Licenciatura em Química, Instituto Federal de Pernambuco - Campus Vitória de Santo Antão, quimicagiselly@gmail.com

2 Mestrado em Estatística, Universidade Federal Rural de Pernambuco, dinhosax14@hotmail.com

3 Docente, Instituto Federal de Pernambuco - Campus Vitória de Santo Antão, aguinalda.alves@vitoria.ifpe.edu.br

${ }^{4}$ Doutora em Nutrição, Instituto Federal de Pernambuco - Campus Vitória de Santo Antão, ana.falcao@vitoria.ifpe.edu.br
} 
professores, a falta de interesse e desmotivação por parte dos estudantes, levam os professores a procurarem cada vez, a inovação em sala de aula. Dentre os recursos utilizados pelos professores para auxiliar no ensino-aprendizagem estão: uso de tecnologia, de experimentos laboratoriais, visitas técnicas, jogos didáticos, situações do cotidiano.

A dificuldade no ensino-aprendizagem de química pode está associada a questões como: Para que serve a química? Por que eu tenho que aprender química? Onde vou usar a Química na minha vida? Indagadas pelos estudantes aos professores que muitas vezes não sabem responder, ou acham desnecessário responder tais perguntas.

Alguns alunos consideram a disciplina desinteressante ou sem utilidade em sua vida cotidiana. A forma como a matéria é apresentada e a dificuldade em sua assimilação, desestimulam e contribuem para a falta de motivação. Observa-se que as justificativas, tanto para a motivação quanto para a desmotivação demonstrada no ensino de química, estão basicamente associadas à presença de três fatores: necessidade/não necessidade; facilidade/dificuldade, e teoria/prática (forma como é apresentada) (CARDOSO; COLINVAUX, 2000).

Sobre as dificuldades de ensinar Ciências Costa (2010) afirma que tal situação pode ser vista com tristeza, o sofrimento que acompanha cada um dos novos professores que passaram pelas escolas. É penoso e desumano. E a cada ano que passa, tendo em vista a pouca orientação educativa que os alunos trazem para a escola, das suas casas, das suas famílias, os novos professores têm passado por dificuldades cada vez maiores para ensinar Ciências.

Mesmo já estando na modernidade, o ensino de Química ainda é marcado pela educação tradicional e conservadora, baseada em repetições e na memorização. Muitas vezes os estudantes se veem "obrigados" a decorar fórmulas, regras e nomes para atingir boa nota nas avaliações.

Na maioria das escolas, o ensino de Química ainda é descontextualizado, e os estudantes na maioria das vezes são desmotivados a aprender uma Ciência que até onde eles sabem, não apresentam nenhum importância e aplicação em sua vida.

Diferente do que os estudantes acreditam, a química é uma ciência de fundamental importância para o desenvolvimento da humanidade, todos os conteúdos podem ser associados à aplicações o cotidiano. Inclusive a radiação nuclear, que é tida por muitos como 
uma química perigosa, que traz grandes riscos à saúde e que no seu ensino é difícil fazer relações com o dia a dia.

Por isso se faz necessário, um ensino de Química que aproxime a ciência ao cotidiano do estudante, e que ele possa ao concluir a Educação Básica ter conhecimentos corretos sobre os processos e tecnologias utilizados na sociedade.

O estudo tem como objetivo investigar as percepções que os estudantes do terceiro ano do Ensino Médio Integrado do Instituto Federal de Pernambuco - Campus Vitória de Santo Antão têm sobre a radiação nuclear, sua utilização em diversos objetos e processos.

\section{Fundamentação Teórica}

Medeiros e Lobato (2010) acreditam que a contextualização no ensino de Química pode oferecera os estudantes a possibilidade de identificar o conteúdo a partir de contextos locais. Sendo assim, a abordagem do conteúdo radiações no Ensino Médio relacionado a alguns fenômenos e avanços tecnológicos pode transformar o ato de ensinar e aprender Química em algo mais agradável e com resultados mais expressivos.

Sem a contextualização no ensino, os estudantes tendem a apenas memorizar os conteúdos para as avaliações, esquecendo do assunto logo após a realização da prova. Assim, a Educação Básica perde seu sentido visto que os estudantes saem para o Ensino Superior sem ter noção dos fenômenos químicos, biológicos, físicos, socias, políticos e econômicos que acontecem ao seu redor constantemente, pois durante toda a Educação Básica ele estudou para as provas bimestrais sem fazer relação com o seu cotidiano.

Muitas pessoas têm medo da radiação nuclear e dos perigos que ela pode trazer a saúde, no entanto, atualmente a radiação nuclear é responsável pelo desenvolvimento de várias áreas como: descoberta e tratamento de doenças, geração de energia, datação de fósseis, conservação de alimentos entre outras.

Para Kelecom e Gouveia (2002) a imprensa tem uma profunda responsabilidade sobre esse medo que a população tem a respeito da radiação, pois o caráter sensacionalista invariavelmente embutido nas notícias sobre o "nuclear" pouco contribui para o esclarecimento do público leigo, fazendo com que a palavra radioatividade se torne sinônima de "coisa ruim".

Segundo Mazzilli et al. (2002) tudo que existe na natureza tende a permanecer num estado estável. Os átomos instáveis passam por um processo que os tornam mais estáveis. 
Este processo envolve a emissão do excesso de energia do núcleo e é denominado radioatividade ou decaimento radioativo. Portanto, a radioatividade é a alteração espontânea de um tipo de átomo em outro com a emissão de radiação para atingir a estabilidade. A energia liberada pelos átomos instáveis, radioativos, é denominada radiação ionizante. Os termos radiação e radioativo frequentemente são confundidos. Deve-se ter sempre em mente que estes dois termos são distintos: átomos radioativos são aqueles que emitem radiação.

\section{Metodologia}

A pesquisa de natureza básica, apresenta uma abordagem quantitativa, de caráter explicativa. Foi realizada no Instituto Federal de Pernambuco - Campus Vitória de Santo Antão.

Teve como sujeitos 60 (sessenta) estudantes do terceiro ano do Ensino Médio Integrado ao técnico de Agroindústria e Agropecuária. A escolha dos sujeitos deu-se pelos os mesmos estarem concluindo a Educação Básica, assim, procurou-se investigar com quais ideias e pensamentos sobre a radiação nuclear os estudantes estão deixando o Ensino Básico.

Aos estudantes foi aplicado um questionário adaptado do estudo de Kelecom e Gouvea (2002), contendo 3 questões: a primeira questionava o primeiro pensamento que o estudante tem quando escuta a expressão "radiação nuclear", a segunda perguntava se existe radiação nuclear natural, e a terceira solicitava que o estudante marcasse um $\mathrm{X}$ no objeto e fenômeno que ele achava que utilizava radiação nuclear.

Entre as opções estavam: armamento, produção de energia, forno, micro-ondas, conservação de alimentos, beneficiamento de pedras semi-preciosas, telecomunicações (rádio, TV, telefone fixo), telefone celular, navegação espacial, navegação marítima, navegação submarina, diagnóstico de doenças, tratamento de doenças, raios-x ou abreugrafia, tomografia computadorizada, relojoaria, proteção como para-raios, envelhecimento de objetos de arte, beneficiamento de vinho, análise laboratorial, imunologia, bioquímica, física, biologia, química, fisiologia, indústrias metalúrgicas.

Os dados foram tabulados e analisados no Excel e distribuído em gráficos e tabela. Todos os estudantes participantes do estudo assinaram o Termo de Consentimento Livre e Esclarecido.

\section{Resultados e Discussão}


O gráfico 1 apresenta o primeiro pensamento dos estudantes quando questionados sobre o uso da radiação nuclear, a maior parte dos alunos afirmaram ter pensamentos negativos sobre o fenômeno, de modo geral.

Mesmo após 120 anos de estudos envolvendo a radioatividade, e com a mesma sendo utilizada beneficamente em diversos tratamentos médicos e processos industrias, além da geração de energia nuclear, a radiação ainda é vista como algo negativo.

O estudo vai de encontro com as observações de Faleiro et al. (2013) que identificou em seu estudo que 56,4\% ( $\mathrm{n}=22)$ dos estudantes da amostra afirmaram que quando ouvem falar em radioatividade o primeiro sentimento que vem a mente é negativo.

Alguns acidentes radioativos ao longo da história podem ser os "culpados" pela radiação nuclear ainda não ser tão bem aceita na população. Dentre as principais tragédias estão: os de Hiroshima e Nagasakino Japão, em 1945; O de Windscale, em 1957 na Inglaterra; O de Three Mile Islandna Pensilvânia em 1979; O de Chernobyl em 1986 na Ucrânia, o de Goiânia-BR em 1987, e o de Fukushima no Japão em 2011 (XAVIER et al., 2007, p. 85-86; SANTOS et al., 2013, p. 68).

Gráfico 1. Primeiro pensamento sobre a radiação nuclear dos estudantes do terceiro ano do Ensino Médio, Instituto Federal de Pernambuco - Campus Vitória de Santo Antão, 2016. Fonte: Própria

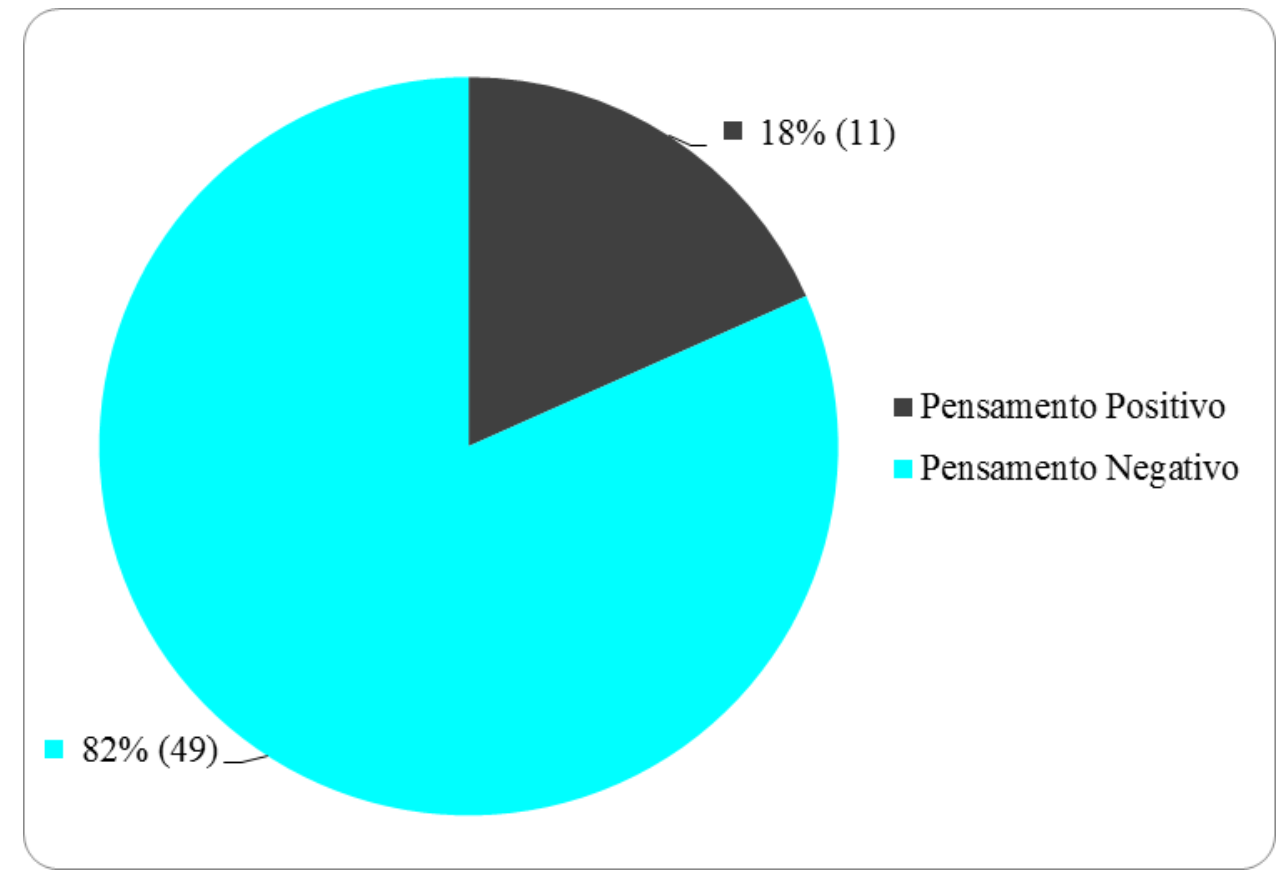

Essa visão sobre a radiação também é observada nos estudos de Kelecom e Gouvea (2002) e Medeiros e Lobato (2010). 
O gráfico 2 apresenta as respostas dos estudantes quando questionados sobre a existência da radiação nuclear natural. A maior parte dos alunos tinham conhecimento sobre a radiação nuclear natural.

As duas maiores fontes de radiação natural são o cosmo, através dos raios cosmos e a biosfera. A radiação nuclear é oriunda de radionuclídeos naturais ou artificiais presentes na bioesfera terrestre, por isso o homem sempre esteve exposto a tais radiações.

Estes radionuclídeos podem ser introduzidos no ecossistema por meio de simples reações físico-químicas que ocorrem naturalmente na água, solo, ar e biota, ou por atividades humanas, alguns pesquisadores veem estudando tais radiações, visto que as fontes naturais transmitem doses de radiações mais altas que a população geralmente recebe. Dentre os principais meios que transferem radiação para o homem, está a água. Por isso, analises para a determinação de radioisótopos na água de beber é de vital importância (OLIVEIRA, 1998, p. 1).

Gráfico 2. Respostas dos estudantes sobre a existência da radiação natural, Instituto Federal de Pernambuco Campus Vitória de Santo Antão, 2016. Fonte: Própria

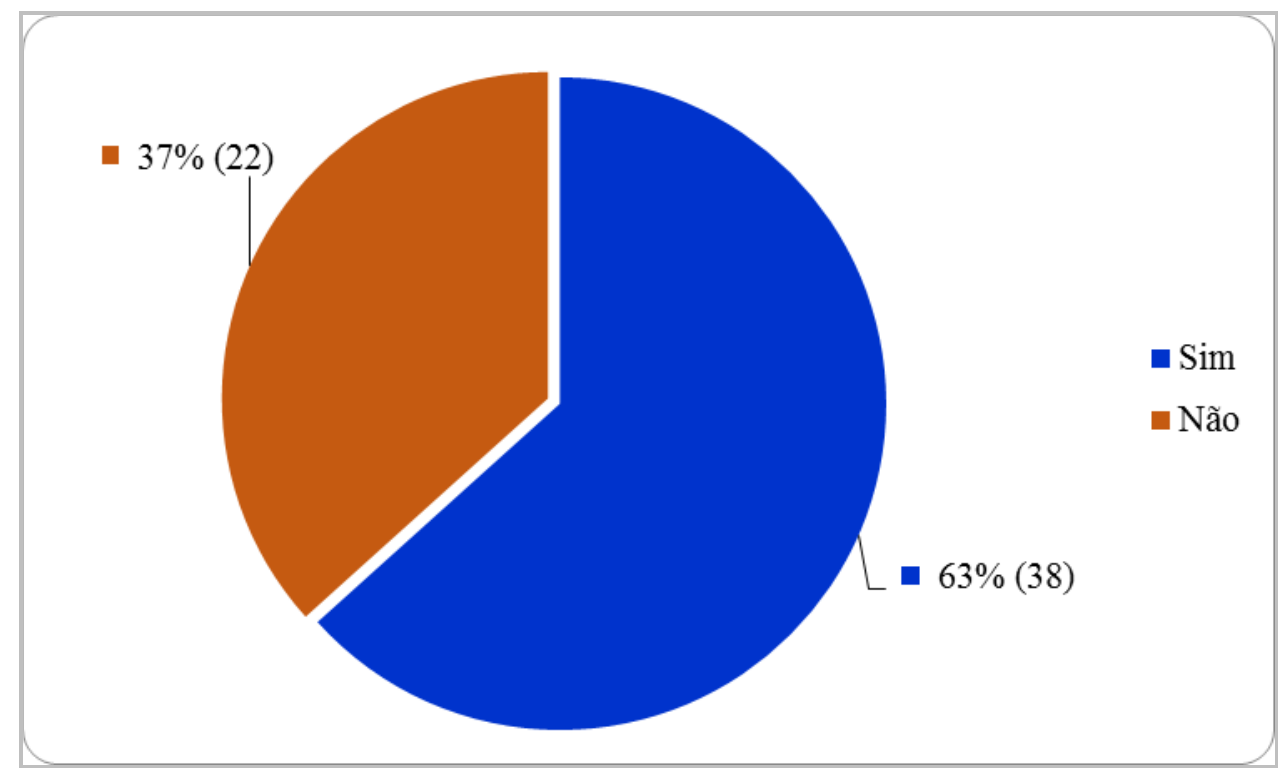

A tabela 1 apresenta os números absolutos e relativos de alunos que acreditam que há radiação nos objetos e processos descritos. Essa questão teve como objetivo identificar a presença da radioatividade em diversos objetos e processos.

Todos os estudantes identificaram a presença da radiação em exames de raio-x. Em 
segundo lugar os estudantes associaram a radioatividade ao celular, forno microondas e a produção de energia com 78,3\% (n=47). Em terceiro lugar ficaram as aplicações nos meios de telecomunicações (rádio, TV, telefone fixo) com 71,6\% ( $\mathrm{n}=43)$.

Esperava-se obter como as principais aplicações da radiação a produção de energia, a produção de armamentos (bombas atômicas) e nos diagnósticos e tratamentos de doenças, como o câncer. Visto que são temas frequentemente expostos nos principais meios de comunicação do país.

Ressalva-se a associação errônea dos raios-x a radiação nuclear, Chassot (1995) explica que raios $\mathrm{X}$ são radiações eletromagnéticas com comprimento de onda no intervalo aproximado de $10^{-11}$ a $10^{-8} \mathrm{~m}(0,1$ a $100 \AA$ ), resultantes da colisão de elétrons produzidos em um cátodo aquecido (ocorre uma emissão termoiônica) contra elétrons de um ânodo metálico, diferenciando-se assim, das radiações, originadas nos núcleos atômicos, com as quais se assemelham em intensidade, os raios $\mathrm{X}$ têm origem extra-nuclear.

Em seu estudo Bez et al. (2013) também identificou que os estudantes associam o raio x à radiação nuclear. Sinoti e Oliveira (2013) explicam que O equipamento de raio X não possui

material radioativo, nem gera rejeito radioativo, apesar de somente diferirem da radiação gama pela origem. Como os raios-X não saem do núcleo do átomo, não são considerados energia nuclear, sendo gerados quando elétrons são emitidos, acelerados por alta voltagem, e lançados contra átomos, sofrendo frenagem e perdendo energia.

Dentre as aplicações que foram menos citadas estão, o beneficiamento do vinho com apenas 3,3\% (n=2), utilização na fisiologia e imunologia com 6,6\% (n=4), e em relojoaria com $15 \%(\mathrm{n}=9)$.

Chama-se atenção para a conservação de alimentos, em que apenas $30 \%$ dos estudantes têm conhecimento sobre a utilização da radiação no processo. Em um estudo realizado com 320 estudantes do Ensino Médio por Dutra (2010) identificou-se que $71 \%$ dos sujeitos consumiria alimento irradiado, a maior parte alegou que tais alimentos não oferecem riscos à saúde. As tecnologias contemporâneas como as telecomunicações, aparelho celular e forno microondas foram associados erroneamente de modo significativo a aplicação nuclear. 
Tabela 1. Número de estudantes que acreditam na presença da radiação nuclear nos objetos e fenômenos apresentados. Fonte: Própria

\begin{tabular}{|c|c|c|c|}
\hline $\begin{array}{l}\text { Número } \\
\text { de ordem }\end{array}$ & $\begin{array}{c}\text { Aplicação da } \\
\text { radiação nuclear }\end{array}$ & $\begin{array}{l}\text { Número de estudantes que } \\
\text { acreditam na presença da } \\
\text { radiação no processo }\end{array}$ & $(\%)$ \\
\hline 1 & Armamento & 20 & 33,3 \\
\hline 2 & $\begin{array}{l}\text { Produção de } \\
\text { energia }\end{array}$ & 47 & 78,3 \\
\hline 3 & Forno microondas & 51 & 85 \\
\hline 4 & $\begin{array}{l}\text { Conservação de } \\
\text { alimentos }\end{array}$ & 18 & 30 \\
\hline 5 & $\begin{array}{l}\text { Beneficiamento de } \\
\text { pedras (semi)- } \\
\text { preciosas }\end{array}$ & 13 & 21,6 \\
\hline 6 & $\begin{array}{l}\text { Telecomunicações } \\
\text { (rádio, TV, telefone } \\
\text { fixo) }\end{array}$ & 43 & 71,6 \\
\hline 7 & Telefone celular & 47 & 78,3 \\
\hline 8 & Navegação espacial & 24 & 40 \\
\hline 9 & $\begin{array}{l}\text { Navegação } \\
\text { marítima }\end{array}$ & 14 & 23,3 \\
\hline 10 & $\begin{array}{l}\text { Navegação } \\
\text { submarina }\end{array}$ & 13 & 21,6 \\
\hline 11 & $\begin{array}{c}\text { Diagnóstico de } \\
\text { doenças }\end{array}$ & 41 & 68,3 \\
\hline 12 & $\begin{array}{c}\text { Tratamento de } \\
\text { doenças }\end{array}$ & 33 & 55 \\
\hline 13 & $\begin{array}{l}\text { Raios-X ou } \\
\text { Abreugrafia }\end{array}$ & 60 & 100 \\
\hline 14 & $\begin{array}{c}\text { Tomografia } \\
\text { computadorizada }\end{array}$ & 39 & 65 \\
\hline 15 & Relojoaria & 9 & 15 \\
\hline 16 & $\begin{array}{l}\text { Proteção como } \\
\text { pára-raios }\end{array}$ & 27 & 45 \\
\hline 17 & Envelhecimento de & 10 & 16,6 \\
\hline
\end{tabular}




\begin{tabular}{|c|c|c|c|}
\hline & objetos de arte & & \\
\hline 18 & $\begin{array}{c}\text { Beneficiamento de } \\
\text { vinho }\end{array}$ & 2 & 3,3 \\
\hline 19 & Análise laboratorial & 33 & 55 \\
\hline 20 & Imunologia & 4 & 6,6 \\
\hline 21 & Bioquímica & 32 & 53,3 \\
\hline 22 & Física & 14 & 23,3 \\
\hline 23 & Biologia & 19 & 31,6 \\
\hline 24 & Química & 33 & 55 \\
\hline 25 & Fisiologia & 4 & 6,6 \\
\hline 26 & $\begin{array}{c}\text { Indústrias } \\
\text { metalúrgicas }\end{array}$ & 34 & 56,6 \\
\hline
\end{tabular}

Sobre o ensino-aprendizagem da radioatividade no Ensino Médio Mota e Duarte (2015) discursam que,

a radioatividade tem sido abordada de forma geral, em livros de química do ensino médio e na sala de aula, com pouca ênfase histórica e grande ênfase aos conceitos (leis da radioatividade, cinética das desintegrações, meia-vida, etc.), estas formas de abordagens são tradicionais e "conteudistas", passíveis de crítica, pois alguns fatos como os acidentes, guerras, desastres, datação de fósseis e radiologia citados anteriormente, que podem ser classificados como acontecimentos históricos e avanços tecnológicos, podendo estes ser utilizados como meio de transposição didática, sendo capaz de estimular significativamente os alunos, pouco se encontram nos materiais didáticos sendo também muito pouco mencionados pelos professores durante suas aulas. dessa forma o aluno não terá uma visão crítica sobre o 314 tema, não será ativo e sim um memorizador. Decorando as leis e fórmulas para um vestibular o que leva ao velho questionamento: "o que isso vai ajudar na minha vida?" (MOTA e DUARTE, 2015).

Cardoso e Costa (2012) acreditam que a abordagem da radioatividade nas escolas desde o Ensino Fundamental é de extrema importância, pois quando tratado com coerência pode desmistificar alguns conceitos errôneos e também, fazer com que os mesmos sejam conhecidos e compreendidos de forma correta. Além disso, assuntos com a repercussão e importância social, como o tratado nesse trabalho, dizem respeito a cada indivíduo, que deve ser capaz de opinar, agir e decidir de acordo com os conhecimentos por eles construídos. 


\section{Conclusões}

Percebe-se que existe uma troca de conceitos referentes ao conceito de radiação, que é utilizado por muitas pessoas de forma errônea. Nem toda radiação é nuclear, aparelhos como rádio, televisão celular emitem radiação eletromagnética que se difere daquela radiação emitida pelo núcleo atômico.

A maior parte dos estudantes têm o primeiro pensamento sobre a radioatividade, negativo. O histórico de acidentes e as informações passadas pela mídia, favorecem para que a radiação nuclear seja vista como algo de impacto negativo na sociedade, no entanto os benefícios trazidos pela radiação na saúde, na produção de energia e conservação de alimentos não podem ser esquecidos.

O campo de estudo da radiação é relativamente novo, muitas coisas ainda são uma incógnita para o homem, que deve utilizar a radiação com cautela.

\section{Referências}

BEZ, T. V.; ALEXANDRE, W.; COSTA, S. A radioatividade na visão dos alunos de um curso de licenciatura em Ciências da Natureza. In: Simpósio De Integração Científica E Tecnológica Do Sul Catarinense - SICT-Sul, 2., 2013, Santa Catarina. Anais...Santa Catarina: UFSC, 2013, p. 514-523.

CHASSOT, A. Raio X e Radioatividade. Química Nova na Escola, n. 2, nov. 1995.

CARDOSO, H. C.; COSTA, S. Representações sociais sobre radioatividade dos alunos do ensino médio. Rev. Técnico Científica (IFSC), v. 3, n. 1, 2012, p. 401-411.

CARDOSO, S. P.; COLINVAUX, D. Explorando a motivação para estudar química. Quím. Nova, v. 23, n. 3, São Paulo, Mai-Jun, 2000.

COSTA, N. L. A Formação do Professor de Ciências para o Ensino da Química do $9^{\circ}$ ano do Ensino Fundamental - A Inserção de uma Metodologia Didática Apropriada nos Cursos de Licenciatura em Ciências Biológicas. 2010. 77 p. Dissertação. (Mestrado Ensino das Ciências na Educação Básica). Universidade do Grande Rio "Prof. José de Souza Herdy".

DUTRA, P. M. B. F. Percepção de estudantes do ensino médio sobre o tema "radiação" e tecnologias relacionadas: ideias informais e categorias conceituais. 2010. 138 p. Dissertação (Mestrado em Ciência e Tecnologia das radiações, minerais e materiais) - Comissão Nacional de Energia Nuclear, Belo Horizonte, 2010.

FALEIRO, J. H.; COSTA, D. R. O.; MAGAlHÃES, T. L. P. GONÇALVES, R. C.; MÁXIMO, N. C. L. Avaliação do nível de conhecimento de estudantes de Licenciatura em 
Química (IF Goiano - Câmpus Urutaí) sobre a radioatividade. Enciclopédia Biosfera, Centro Científico Conhecer - Goiânia, v.9, n.16; p. 2016- 2327, 2013.

KELECOM, A.; GOUVEA, R. C. S. A Percepção da Radioatividade por Estudantes de Nível Superior. Mundo \& Vida, v. 3, n. 2, p. 78-89, 2002.

MAZZILLI, B. P.; FILHO, C. R.; KODAMA, Y.; SUZUKI, F. F.; DELLAMANO, J. C.; MARUMO, J. T.; SANCHES, M. P.; VICENTE, R.; BELLINTANI, S. A. Noções Básicas de Proteção Radiológica. Instituto de Pesquisas Energéticas e Nucleares, 2002.

MEDEIROS, M. A.; LOBATO, A. C. Contextualizando a abordagem de radiações no ensino de química. Rev. Ensaio, Belo Horizonte, n. 3, V. 12, p.65-84, 2010.

MOTA, M. M.; DUARTE, A. R. Ensino de radioatividade: uma proposta interdisciplinar e contextualizada. In: Encontro De Profissionais Da Química Da Amazônia, 14., 2015, Belém. Anais... Belém: CRQ, 2015, p. 307-320.

OLIVEIRA, J. Determinação dos níveis de radioatividade natural presente nas águas utilizadas para abastecimento público no estado de São Paulo. 1998. 159 p. Tese (Doutorado em Ciências na área de Tecnologia Nuclear-Aplicações) - Instituto de Pesquisas Energéticas e Nucleares, São Paulo, 1998.

SANTOS, P. N. C.; SOUZA, V. L. B. Fukushima: Após um ano do acidente, quais as influências nos meios: físico, biológico e antropogênico? Cadernos de Graduação Ciências Biológicas e da Saúde Facipe, Recife, n.1, v. 1, p. 67-73, ago. 2013

SINOTI, A.L.L.; OLIVEIRA, M.C. Resíduos químicos e os rejeitos radioativos nos serviços de saúde. RQI, $1^{\circ}$ trimestre, p. 16-22, 2013.

XAVIER, A. M.; LIMA, A. G.; VIGNA, C. R. M.; VERBI, F. M.; BORTOLETO, G. G.; GORAIEB, K.; COLLINS, C. H.; BUENO, M. I. M. S. Marcos da história da radioatividade e tendências atuais. Quim. Nova, v. 30, n. 1, p. 83-91, 2007. 